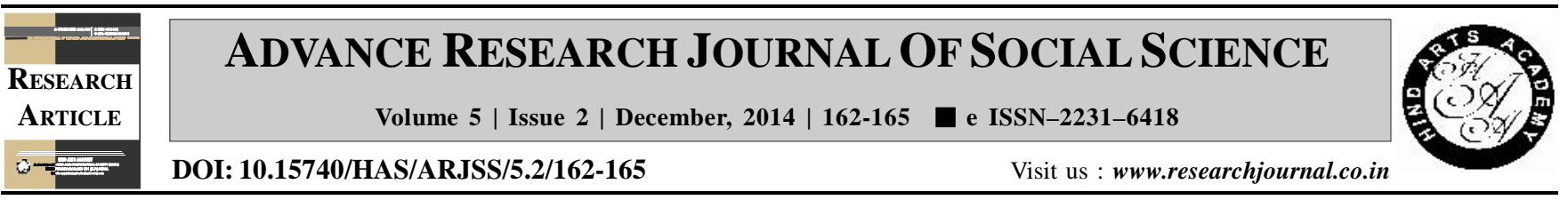

\title{
Study of the role of the accredited social health activist (ASHA) in reducing maternal mortality rate in Tumkur district of Karnataka
}

N. Kumara* and Nehal A. Farooquee

Department of Extension and Development Studies, Indira Gandhi National Open University, NEW DELHI (INDIA) (Email: nkumar278@gmail.com)

\section{ARTICLE INFO :}

$\begin{array}{lll}\text { Received } & : & 21.07 .2014 \\ \text { Revised } & : & 01.11 .2014 \\ \text { Accepted } & : & 14.11 .2014\end{array}$

KEY WORDS :

MMR, IMR, Public health system, ASHA, Institutional deliveries

HOW TO CITE THIS ARTICLE :

Kumara, N. and Farooquee, Nehal A. (2014). Study of the role of the accredited social health activist (ASHA) in reducing maternal mortality rate in Tumkur district of Karnataka. Adv. Res. J. Soc. Sci., 5 (2) : 162-165.

*Author for correspondence

\begin{abstract}
ASHA, the mechanism to strengthen the village level service delivery, will be a local resident and selected by the Gram Panchayat or the Village Health Committee (VHC). She will be supported in her work by the AWW, school teacher, members of local community based organizations, such as SHGs, and the Village Health committee. ASHA's role would be to facilitate care seeking and serve as a depot holder for a package of basic medicines. She will be reimbursed on a performance based remuneration plan. ASHA workers play a pivotal role as the primary interface between the communities and the public health system. Women, children and adolescents form the core of the society. A substantial portion of ASHA workers interaction is with the women and children. A positive impact on this targeted population will have long lasting results on the health, wellbeing and productivity. The study has clearly shown that institutional deliveries increased and MMR significantly reduced to 79 against the 106 of last year.
\end{abstract}

